\title{
Reliability and Maintainability Analysis of Crushing Plants in Jajarm Bauxite Mine of Iran
}

\author{
Javad Barabady, Luleå University of Technology
}

Key words: Reliability Analysis, Crushing Plant, Mine

\section{SUMMARY}

Reliability is an important consideration in the planning, design and operation of engineering systems. As the size and complexity of mining equipment continue to increase, the implications of equipment failure become ever more critical. An unplanned failure can result in significantly higher repair costs than a planned maintenance or repair. Of even more importance is the loss of production associated with larger equipment failures. One method to mitigate the impact of failures is to improve the reliability of the equipment. Reliability is a performance indicator of overall equipment condition. A first step in reliability improvement is collection and analysis of the appropriate data.

This paper presents a case study describing reliability analysis of crushing plants in Jajarm bauxite mine. In this study crushing plants are divided into seven subsystems. Reliability analysis has been done for each subsystem by using failures data. The parameters of some idealized probability distributions, such as Weibull, Exponential, Lognormal distributions, have been estimated by using ReliaSoft's Weibull++ 6 software. An investigation has also been made to determine which of these distributions provide the best fit for characterizing the failure pattern of the two crushing plants and their subsystems. Some aspects of system failure behavior are analyzed briefly for ongoing machine improvement. Reliability of both crushing plants and its subsystems has been estimated at different mission times with their best fit distribution. Analysis of the total downtime, breakdown frequency, reliability, and maintainability characteristics of different subsystems shows that the reliability of crushing plant 1 and crushing plant 2 after 10 hour reduce to about $64 \%$ and $35 \%$ respectively. The study shows that reliability and maintainability analysis is very useful for deciding maintenance intervals. It is also useful for planning and organizing maintenance.

\section{INTRODUCTION AND BACKGROUND}

Reliability is a property of an item or service that we all desire, but all too often find is missing. The reliability of a product is the measure of its ability to perform its function, when required, for a specified time, in a particular environment [1]. It is measured as a probability. From an economic point of view, high reliability is desirable to reduce the maintenance costs of the systems. The reliability analysis of equipment can broadly be divided into two major groups:

- Machine reliability

- Software reliability in the case of automatic operations

The system reliability, maintainability and availability (RAM) have assumed great significance in recent years due to competitive environment and overall operating production cost. Performance of a mining machine depends on reliability of the equipment used, mining environment, maintenance efficiency, operation process and technical expertise of miner, etc. The study of a machine's reliability is needed to determine the necessary improvement or modification to control the competitive pressure in the marketplace. So a few studies in this regard, particularly underground mining machines such as load haul dump (LHD) and Longwall face equipment, have been done. Kumar et al [2,3] and Paraszczak et al [4] carried out reliability based investigation of diesel operated LHD machines in an underground mine. In these studies, graphical and analytical techniques have been used to fit probability distributions for characterization of failure data. The reliability of mining equipment is affected by a variety of factors:

- The actual design of the equipment: how adequate the original design was for the equipment's application dictates the ultimate reliability that can be achieved.

- How well the equipment is maintained: every time a repair, planned or unplanned, is made the quality of repair will influence how long the machine operates before the next repair. This includes the quality of the workmanship and replacement part(s).

- The operating conditions: this includes the environment and operational issues.

The main objectives of studies are:

- To increase understanding of the nature of the failures pattern of crushing plant of complex mining equipment.

- To estimate the reliability and maintainability characteristics of crushing plant in absolute quantitative terms.

- To identify the critical subsystems which require further improvement through effective maintenance policies to enhance the operational reliability of mining operation, faults and formulate a reliability-based maintenance policy.

\section{RELIABILITY OF MACHINE}

The reliability of a machine is the probability that the machine will perform a required function adequately and 
satisfactorily under the stated operational and environmental conditions for a specified period of time. A machine has an inherent reliability created at the design stage. So machine reliability study is necessary for equipment design, modification, and quality control during manufacturing, field trials and life testing, etc [5]. Before the analyzing the failure data, the overall system is better to be classified into subsystems so that the failures can be categorized. The classification used for the reliability and maintainability analysis of the crushing plant is presented in Table 1 .

Table 1 Subsystems of the crushing plant and their code

\begin{tabular}{|c|l|c|}
\hline No & \multicolumn{1}{|c|}{ Subsystem } & Code \\
\hline 1 & Feeder system & FECS \\
\hline 2 & Conveyer System & COCS \\
\hline 3 & Primary Crusher System & PCRCS \\
\hline 4 & Secondary Crusher System & SCRCS \\
\hline 5 & Primary Screen System & PSCCS \\
\hline 6 & Secondary Screen System & SSCCS \\
\hline 7 & Other System & OTCS \\
\hline
\end{tabular}

\section{METHODOLOGY \& DATA COLLECTION}

\subsection{Methodology}

The reliability and maintainability characteristic of a piece of equipment can be determined, respectively, by the analysis of time to failure data and the time taken to repair it. The methodology, which can be followed for the reliability and maintainability analysis of the crushing plant, comprises:

- understanding of the system and identification and coding of subsystems and fault therein,

- collection, sorting and classification of TBF data for each subsystem and fault,

- data analysis for verification of the identically and independently distributed assumption,

- fitting of the TBF and TTR data for subsystems and faults with a theoretical probability distribution,

- estimation of the reliability and maintainability parameters of each subsystem with a best-fit distribution,

- identification of critical subsystems and faults and formulation of a better maintenance policy to improve reliability.

\subsection{Data Collection \& Data Evaluation}

Three basic steps must be performed before the data can be analyzed to determine reliability and maintainability characteristics. These are data collection from a computerized equipment maintenance system (database) or logbook, sorting of the data required for analysis and data classification in the form required for the analysis (i.e. TBF, TTR, frequency, total breakdown hours, total working hours, total maintenance hours, etc)[6]. There are many sources of data in mine equipment, which are of relevance to reliability modeling of equipment. In addition to the information generated by maintenance and production functions in the form of reports, much of the raw data upon which these reports are based must also be accessible in order to achieve successful reliability modeling. Hence reliability modeling can be viewed as an integral part of a unified "analysis" function, dealing with a myriad of information flows including [7, 8]:

- Data from sensors on equipment.

- Data and information from operator interfaces on-board equipment.

- Historical operational and maintenance information.

- Current operational and maintenance information.

Collection of quality failure data is usually necessary in system reliability analysis for getting reliable and accurate results. Data collected from the field are assumed to be the best. Field data are, however, expensive and time consuming to collect. Again, data are required to be collected over a period of time for providing satisfactory representation of the true failure characterization of the mining system. Data used in recent studies have been collected over a period of 8 months by using daily report and maintenance report. Failure behavior of critical subsystems of a crushing plant has an influence on availability or the failure pattern of the system as a whole.

Time between failure (TBF) data of mine operation and its subsystems are arranged in a chronological order for using statistical analysis to determine the trend of failure. The next step after collection, sorting and classification of the data was validation of the independent and identically distributed (iid) nature of the TBF data of each subsystem of both crushing plants. The meaning of sample independence is that the data are free of trends and that each failure is independent of the preceding or succeeding failure. Identically distributed data means that all the data in the sample are obtained from the same probability distribution. Verification of the assumption that the failures/repairs are independent and identically distributed is critical. If the assumption that the data are independent is not valid, than classical statistical techniques for reliability analysis may not be appropriate. Two common graphical methods used to validate the iid assumption are the trend test and the serial correlative test. The trend test involves plotting the cumulative failure number against cumulative time between failures [10]. The serial correlation test is a plot of data pairs $(\mathrm{Xi}, \mathrm{Xi}-1)$ for $\mathrm{i}=1,2 \ldots \mathrm{n}$, where $\mathrm{n}$ is the total number of failures. If $X$ is dependent or correlated, the points should lie along a line. Trend tests and serial correlation tests were carried out on TBF data of the two crushing plants. Due to paucity of space, trend tests of PCRCS, PSCCS, and FECS of crushing plant 2, and PCRCS of crushing plant 1 for example, are shown in Fig. 1. In the test, weak or no absolute trends were found for crushing plants subsystems except PSCCS and SSCCS subsystems of both crushing plants. PSCCS and SSCCS exhibited concave upward. In the serial correlation test, the points are randomly scattered in the case of both crushing plants subsystems, which exhibited no trend. For example, the serial correlation test of PCRCS and SCRCS of crushing plant 2 is given in Fig. 2. So the above failure data can be assumed to be independently and identically distributed (iid).

\section{DATA ANALYSIS}

\subsection{Analysis of trend free data}


The trend free data are further analyzed to determine the accurate characteristic of failure time distributions of crushing plant subsystems for estimating the reliability. The idealized probability distributions are commonly used to describe time between failure data set for crushing plants. Different types of statistical distributions were examined and their parameters are estimated by using ReliaSoft's Weibull++ 6 software.
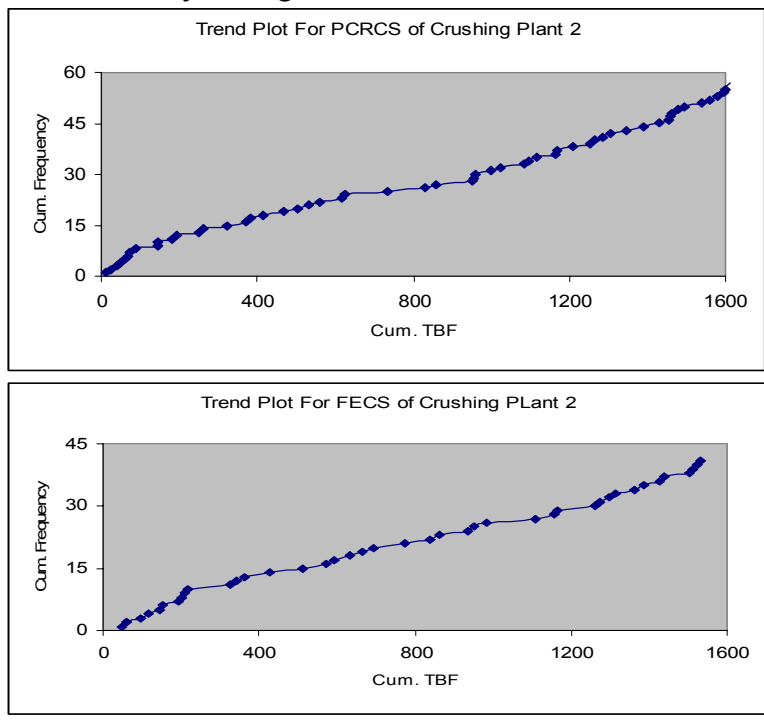

Figure. 1. Trend plot for TBF for some subsystems of both crushing plants

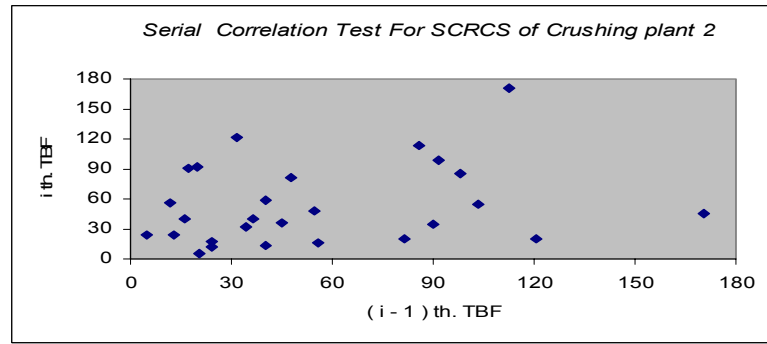

Figure 2. The serial correlation test for SCRCS and COCS of crushing plant 2

\subsection{Analysis of data with trend}

The TBF data set for PSCCS and SSCCS of the two crushing plants exhibit presence of trends in trend test so the assumption of independently and identically distributed (iid) is not valid for the above cases. These subsystems should be analyzed by a non-stationary model such as the non homogeneous Poisson process (NHPP). In this study, power law process NHPP model is used for reliability modeling of the PSCCS and SSCCS of both crushing plants. For the case, the intensity function is given by:

$$
\begin{array}{r}
\lambda_{(t)}=\left(\frac{\beta}{\eta}\right) \times\left(\frac{t}{\eta}\right)^{(\beta-1)} \\
\eta=\frac{t_{n}}{n^{1 / n}} \\
\beta=n /\left[\sum=n /\left[\sum \ln \frac{t_{n}}{t_{i}}\right]\right]
\end{array}
$$

$\beta=$ shape parameter

$\eta=$ scale parameter

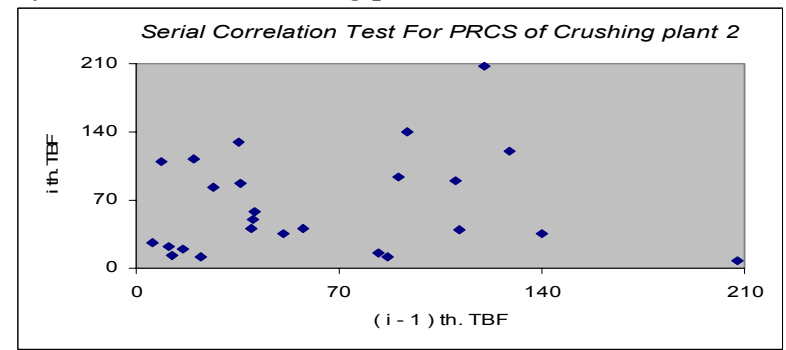

Software fits several distribution models based on the data, by a number of different methods. The user can then choose a preferred model, or accept the model recommended by the software. The results are shown in Table 2. Table 2 it shows the best fit model distributions for each subsystem and describe the failure mechanism of the crushing plant subsystem.
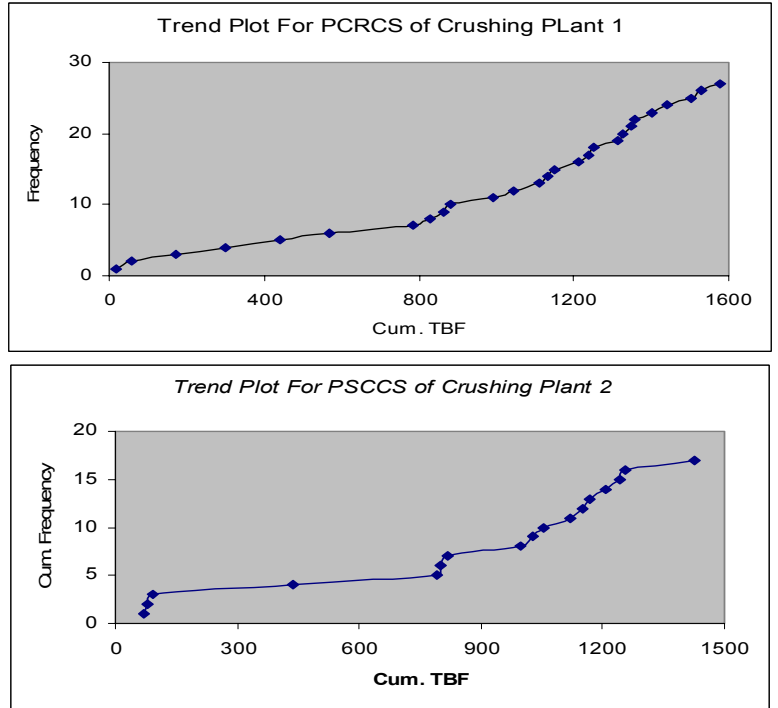

$\mathrm{n}=$ number of failure events,

$t_{\mathrm{n}}=$ total running time,

$\mathrm{t}_{\mathrm{i}}=$ running time at the occurrence of failure number,

$\mathrm{i}=1,2,3 \ldots \mathrm{n}$.

It is very important to check whether the power law process assumption is realistic before using that model for data analysis [10]. Goodness-of-fit test have done by TTT-plot based on power law process for their subsystem and it is found that power law process is valid for PSCCS and SSCCS subsystems of both crushing plants. The above parameters for PSCCS and SSCCS of both crushing plants are estimated from failure data and shown in Table 2. From Table 2, the following points are found:

- In Weibull analysis, the failure rate for COCS, FECS and OTCS of crushing plant 1 and SCRCS and OTCS of crushing plant 2 give a shape parameter more than one indicating increasing failure rate due to aging process.

- The shape parameter of PCRCS of crushing plant 2 indicates a constant failure rate as they reach the useful life or steady state condition

When a crushing plant is put into operation, there are various factors, which may cause to increase the load, or to 
reduce the strength expected. Failure rate of a crushing plant generally depends on time and operating environment at which the crushing plant is used. The environmental condition between mining and other industries is different. Mining in general and underground mining in particular are associated with various types of environmental problems. Crushing plant operated in a mine encounters various types of environmental stress such as ore properties, humidity, high temperature, toxic fumes, specific place for operation and maintenance, dust, etc. These environmental stresses contribute significantly to increase the machine failure rate. When the age of a crushing plant is older, its ability to resist stress decreases, i.e. strength deteriorates. At the time, when the above resistance ability or strength drops below applied stress, the crushing plant fails.

Again, crushing plant failures are due to a combination of

Table 2 Best - fit distribution for TBF data-sets

\begin{tabular}{|c|c|c|c|}
\hline Name & Subsystem & Best-fit distribution & Parameters \\
\hline \multirow{7}{*}{ Crushing plant 1} & PCRCS & Exponential 2 parameter & Lambda $=0.011 ;$ Gamma $=16$ \\
\hline & SCRCS & Lognormal & LMean $=4.416 ;$ LStd $=1.062$ \\
\hline & PSCCS & Non iid, NHPP, Power Low Process & $; \quad$ Eta $=301.38$ \\
\hline & SSCCS & Non iid, NHPP, Power Low Process & $; \mathrm{Eta}=252.13$ \\
\hline & COCS & Weibull 2 parameter & $; \mathrm{Eta}=51.675$ \\
\hline & FECS & Weibull 2 parameter & $;$ Eta $=240.52$ \\
\hline & OTCS & Weibull 2 parameter & ; $\mathrm{Eta}=177.65$ \\
\hline \multirow{7}{*}{ Crushing plant 2} & PCRCS & Weibull 2 parameter & ; Eta $=57.5064$ \\
\hline & SCRCS & Weibull 2 parameter & Beta $=1.4134 ;$ Eta $=55.1876$ \\
\hline & PSCCS & Non iid, NHPP, Power Low Process & ; Eta $=78.62$ \\
\hline & SSCCS & Non iid, NHPP, Power Low Process & $; \quad$ Eta $=38.35$ \\
\hline & COCS & Lognormal & LMean $=3.162 \quad ;$ LStd $=1.3902$ \\
\hline & FECS & Exponential 2 parameter & Lambda $=0.017 ;$ Gamma $=1.98$ \\
\hline & OTCS & Weibull 2 parameter & $\mathrm{Eta}=153.4386$ \\
\hline
\end{tabular}

several causes. These may be due to (i) design inadequacy (ii) operational overstress (iii) wear/abrasion/erosion (iv) corrosion (v) fatigue (vi) creep, etc.

\section{CRUSHING PLANT RELIABILITY ESTIMATION}

The steps involved in reliability evaluation of a system are: (a) Clear definition of the system and its requirement; $(b)$ Identification of the subsystems and the logical configuration in which they are connected; $(c)$ Reliability estimation of each subsystem through the best-fit distribution; (d) Establishing the condition for successful operation of the systems; and (e) Use of the combinational rule of probability theory for system reliability evaluation. [12]

As discussed previously, a crushing plant was taken to comprise seven clearly identifiable subsystems for the purposes of reliability and maintainability analysis. All of these subsystems are functionally arranged in a series configuration, as shown in the simplified reliability block diagram in Fig. 3. This means that the crushing plant is in working condition only when all subsystems are working satisfactorily. The reliability of each crushing plant, as a whole, can be calculated as:

$$
R_{s(t)}=\sum_{i=1}^{5} R_{i}
$$

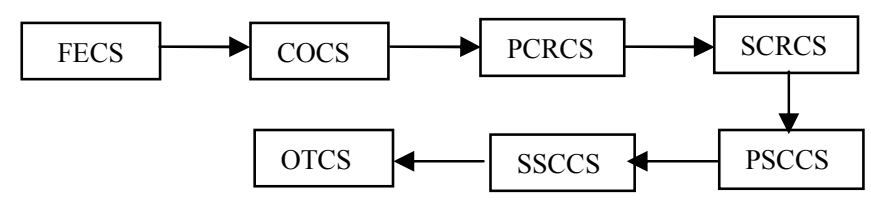

Fig. 3 Simple reliability block diagram of crushing plant where $R_{i}$ is reliability of the different subsystems [10].

The theoretical reliabilities for all seven subsystems at the end of different time intervals were computed with parameters of the best-fit distribution with the aid of ReliaSoft's Weibull ++ 6 software package [Fig 4]. Then the reliability of both crushing plant and its subsystems was calculated and tabulated in Table 3. From Table 3, it is seen that both crushing plant and subsystem reliability decreases as the mission time increase. From Table 3, it is seen that there is only 0.50 probabilities that crushing plant 1 will not fail for 15 hours of operation or there is $70 \%$ chance that the conveyer system of crushing plant 1 will not fail for 20 hours of operation.

\section{MAINTAINABILITY ANALYSIS}

The maintainability of a system is defined as the probability that it can be restored to a specified condition within a given time. The purpose of maintainability engineering is to increase the efficiency and safety and to reduce the cost of equipment maintenance. The measure of the maintenance characteristics of a machine is its maintainability function. The total breakdown hours and number of failures of the different subsystems of both crushing plants were analyzed to identify critical subsystems and faults therein. "Critical" subsystems and faults were defined as those, which have a very high frequency of failure and/or once having failed require a long time to repair and, thus, merit special attention to achieve the desired level of safety and operational effectiveness. The total number of failures (both censored and uncensored) and total breakdown hours attributable to every subsystem of both crushing plants are given in Table 4 . Censored failure data refer to the stoppage of the system, 
which is not due to real failure, e.g. not existence of feed or fuel. The approach to the scheduling of maintenance is based on the concept that every item of equipment has an age at which maintenance is required to ensure safety and operating reliability. A reliability approach to maintenance differs in that it uses probabilistic concepts. In a probabilistic approach a statistical method is employed to fit a theoretical distribution to the failure data. The probability distribution model is then used to predict the failure behavior of the components and to find the preventive maintenance interval that will achieve the

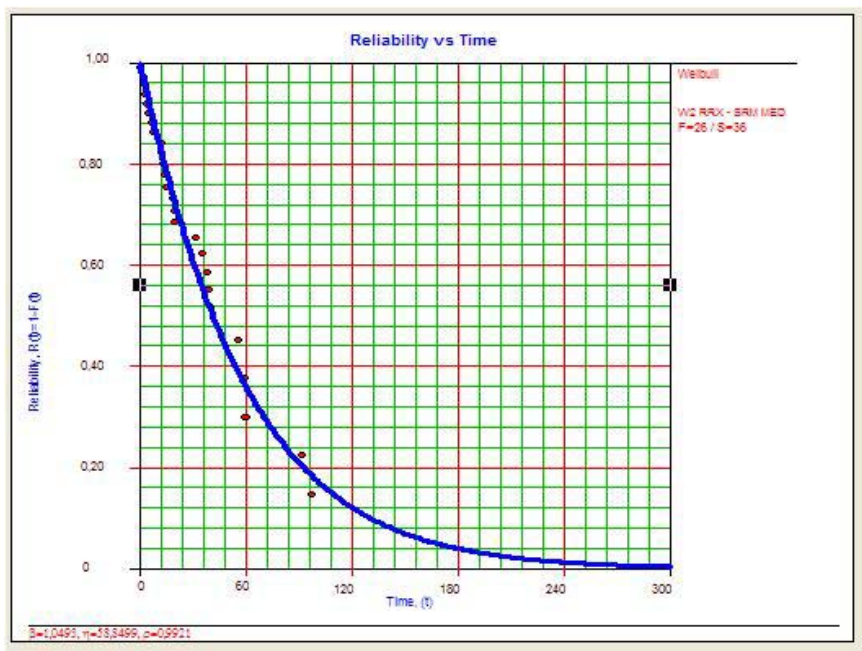

PCRCS desired level of operational reliability of the system.

The maintenance intervals that would achieve different reliability levels in operation were calculated by finding the working hours after which the expected probability of failure of subsystem or fault was $(1-R)$ percent by using the best-fit distribution to the combined TBF data. This was accomplished with the aid of ReliaSoft's Weibull++ 6 software by calculating the values of working hours below which the area of failure in the probability distribution is equal to $R$

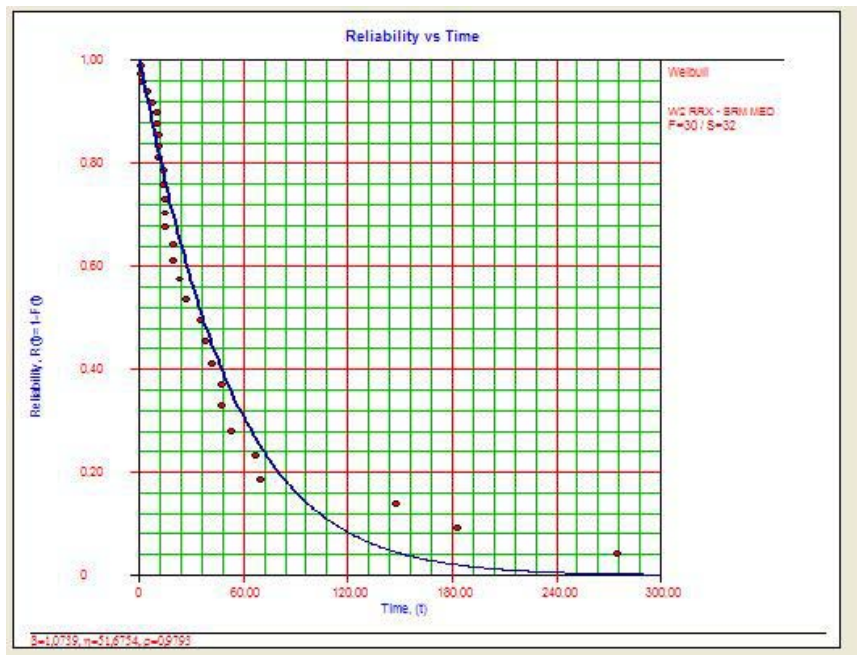

COCS

Fig. 4 Reliability plot for PCRCS of crushing plant 1 and COCS of crushing plant 2

Table 3 Reliability of both crushing plants at the end of different time intervals

\begin{tabular}{|l|c|c|c|c|c|c|c|c|c|}
\hline Name & Time(hour) & PCRCS & SCRCS & PSCCS & SSCCS & COCS & FECS & OTCS & Total \\
\hline \multirow{4}{*}{ Crushing plant 1 } & 0 & 1 & 1 & 1 & 1 & 1 & 1 & 1 & 1 \\
\cline { 2 - 10 } & 5 & 0.9526 & 0.9959 & 0.9667 & 0.9680 & 0.9218 & 0.9960 & 0.9990 & 0.8143 \\
\cline { 2 - 10 } & 10 & 0.9074 & 0.9767 & 0.9346 & 0.9370 & 0.8425 & 0.9894 & 0.9962 & 0.6445 \\
\cline { 2 - 10 } & 15 & 0.8644 & 0.9462 & 0.9035 & 0.9070 & 0.7673 & 0.9811 & 0.9916 & 0.5003 \\
\cline { 2 - 10 } & 20 & 0.8234 & 0.9095 & 0.8734 & 0.8780 & 0.6971 & 0.9717 & 0.9854 & 0.3833 \\
\cline { 2 - 10 } & 30 & 0.7472 & 0.8305 & 0.8162 & 0.8227 & 0.5725 & 0.9500 & 0.9684 & 0.2195 \\
\hline \multirow{4}{*}{ Crushing plant 2 } & 40 & 0.6780 & 0.7533 & 0.7628 & 0.7709 & 0.4679 & 0.9256 & 0.9455 & 0.1230 \\
\cline { 2 - 10 } & 0 & 1 & 1 & 1 & 1 & 1 & 1 & 1 & 1 \\
\cline { 2 - 10 } & 5 & 0.9283 & 0.9670 & 0.9390 & 0.904484 & 0.8680 & 0.9499 & 0.9871 & 0.6205 \\
\cline { 2 - 10 } & 10 & 0.8560 & 0.9145 & 0.8817 & 0.818091 & 0.7318 & 0.8725 & 0.9692 & 0.3494 \\
\cline { 2 - 10 } & 20 & 0.7872 & 0.8533 & 0.8279 & 0.739949 & 0.6280 & 0.8013 & 0.9490 & 0.1965 \\
\cline { 2 - 10 } & 0.7225 & 0.7880 & 0.7774 & 0.669272 & 0.5476 & 0.7360 & 0.9273 & 0.1107 \\
\cline { 2 - 9 } & 40 & 0.6063 & 0.6554 & 0.6854 & 0.547525 & 0.4317 & 0.6209 & 0.8815 & 0.0352 \\
\cline { 2 - 9 } & 0.5068 & 0.5302 & 0.6043 & 0.447925 & 0.3524 & 0.5238 & 0.8338 & 0.0112 \\
\hline
\end{tabular}

The time intervals for different levels of reliability, e.g. $0.95,0.90,0.75$ and 0.50 , are tabulated in Table 5. Thus, to achieve $90 \%$ reliability $(R=0.90)$ for the SCRCS of crushing plant 1, maintenance must be carried out before $21.23 \mathrm{~h}$, because after the machine has run for $21.23 \mathrm{~h}$ without failure there is only a 0.9 probability that it will not fail. The reliability-based time interval was calculated on the basis of the operating characteristics of the crushing plant only as cost data were not available.

The maintenance interval for the different reliability levels listed in Table 5 may be used for inspection, repair, servicing, condition monitoring or replacement depending on the safety implications, cost-benefit considerations and nature of the fault. For a reliability level of $90 \%$, however, the maintenance interval estimated for each subsystem and some critical faults is too short for practical implementation. Therefore, the maintenance interval advocated for a $75 \%$ reliability level may be adopted initially and then, after observation of the benefits obtained in terms of cost, safety and operational effectiveness of the machine, adjusted for a higher value of reliability. 
Table 4 Breakdown time and frequency by subsystem of both crushing plants

\begin{tabular}{|c|c|c|c|}
\hline Name & Subsystem & Frequency & Cum. TTR \\
\hline \multirow{4}{*}{ Crushing Plant 1 } & PCRCS & 27 & 114.27 \\
\cline { 2 - 4 } & SCRCS & 22 & 103.53 \\
\cline { 2 - 4 } & PSCCS & 30 & 66.27 \\
\cline { 2 - 4 } & SSCCS & 20 & 36.81 \\
\cline { 2 - 4 } & COCS & 30 & 36.47 \\
\cline { 2 - 4 } & FECS & 26 & 69.00 \\
\cline { 2 - 4 } & OTCS & 11 & 28.66 \\
\hline \multirow{5}{*}{ Crushing Plant 2 } & PCRCS & 61 & 190.25 \\
\cline { 2 - 4 } & SCRCS & 42 & 121.67 \\
\cline { 2 - 4 } & PSCCS & 22 & 51.83 \\
\cline { 2 - 4 } & SSCCS & 17 & 23.25 \\
\cline { 2 - 4 } & COCS & 44 & 203 \\
\cline { 2 - 4 } & FECS & 41 & 77.88 \\
\cline { 2 - 4 } & OTCS & 13 & 52.3 \\
\hline
\end{tabular}

Table5 Reliability based preventive maintenance time interval

\begin{tabular}{|l|c|c|c|c|}
\hline Name & Subsystem & \multicolumn{3}{|c|}{$\begin{array}{l}\text { Reliability-based maintenance } \\
\text { interval for different } \\
\text { level, hour }\end{array}$} \\
\cline { 3 - 5 } & & 0.9 & 0.75 & 0.5 \\
\hline \multirow{4}{*}{$\begin{array}{l}\text { Crushing } \\
\text { Plant 1 }\end{array}$} & PCRCS & 25.56 & 42.11 & 78.92 \\
\cline { 2 - 5 } & SCRCS & 21.23 & 40.46 & 82.78 \\
\cline { 2 - 5 } & PSCCS & 15.56 & 42.50 & 102.4 \\
\cline { 2 - 5 } & SSCCS & 16.20 & 44.23 & 106.56 \\
\cline { 2 - 5 } & COCS & 5 & 13.8 & 33.3 \\
\cline { 2 - 5 } & FECS & 49.69 & 100.46 & 186.04 \\
\cline { 2 - 5 } & OTCS & 55.46 & 93.25 & 146.97 \\
\hline \multirow{4}{*}{$\begin{array}{l}\text { Crushing } \\
\text { Plant 2 }\end{array}$} & PCRCS & 6.89 & 17.95 & 41.5 \\
\cline { 2 - 5 } & SCRCS & 11.23 & 22.86 & 42.58 \\
\cline { 2 - 5 } & PSCCS & 8.37 & 22.85 & 55.05 \\
\cline { 2 - 5 } & SSCCS & 5.24 & 14.32 & 34.5 \\
\cline { 2 - 5 } & COCS & 3.98 & 9.25 & 23.62 \\
\cline { 2 - 5 } & FECS & 8.17 & 18.89 & 42.73 \\
\cline { 2 - 5 } & OTCS & 26.02 & 57.45 & 114.93 \\
\hline
\end{tabular}

\section{CONCLUSION}

Most of TBF datasets of two crushing plant's subsystems were found to be independent and identically distributed. The Weibull distribution provided the best fit, in most cases, to the TBF datasets. The reliability of crushing plant 1 is more than crushing plant 2 . This is because crushing plant 1 is new in age. The reliability of crushing plant 1 and crushing plant 2 after 10 hours will reduce to about $64 \%$ and $35 \%$ respectively. The maintenance time interval calculated for $75 \%$ reliability and is recommended for adoption at first. It can then be adjusted after consideration the benefits obtained in terms of cost; safety and operational effectiveness of the crushing plant.

\section{ACKNOWLEDGMENT}

The author wishes to acknowledge Professor Uday Kumar and Mr. Behzad Ghodrati of Div. of Operation and Maintenance Engineering - Luleå University of Technology who reviewed the paper and improved it with helpful tips. He also wishes to acknowledge the contribution of Mr. Ramazani of Jajarm Bauxite Mine for data collection for this paper.

\section{REFERENCE}

1. Leitch, R.D, Reliability Analysis for Engineering, Oxford University Press, New York, 1995.

2. Kumar, U., Kelfsjo, B., Granholm, S., "Reliability Analysis of Hydraulic System of LHD Machines Deployed at Kiruna Iron Ore Mine." In Aven T. ed. Reliability Achievement the Commercial Incentive, London, Elsevier Applied Science.

3. Kumar, U., Kelfsjo, B., Granholm, S., "Reliability investigations for a fleet of load haul dump machines in Swedish mine." Reliability Engineering System Safety, 26, 1989, 341-361

4. Paraszczak, J., Perreault, F., "Reliability of diesel powered load-haul-dump machines in an underground Quebec mine." CIM Bull, (March) 1994, 123-127.

5. Samanta, B., "Reliability Analysis of Shovel Machines Used in an Open Cast Coal Mine." Mineral Resources Engineering, Vol. 10, No. 2 (2001) 219-231.

6. Roy, S.K., Bhattacharyya, M.M., Naikan, V.N.A., "Maintainability and reliability analysis of a fleet of shovels." Transactions of the Institute of Mining and Metallurgy, Section A, 1 October 2001, vol. 110, no. 3, pp. 163-171.

7. Hall, R.A., et al, "Reliability Modeling of Surface Mining Equipment: Data Gathering and Analysis Methodologies.” International Journal of Surface Mining, Reclamation and Environment, 2003, Vol. 17, No. 3, pp. 139-155.

8. Hall, R.A., Daneshmend, L.K., Lipseet, M.G., Wong, J., "Reliability Analysis as a Tool for Surface Mining Equipment Evaluation and Selection." CIM Bulletin, Vol. 93, October 2000, pp. 78-82.

9. Kumar, U., Granholm, S., "Some Simple Graphical Method for Reliability Analysis in Mine." Reliability Production and Control in Coal Mines, 1991, PP. 36-41.

10. Kumar, U., Kelefsjö, B., "Reliability analysis of hydraulic system of LHD machine using the power low process model." Reliability Engineering and System Safety, 35, 1992, 217-224.

11. Hall, R.A., Daneshmend, L.K., "Reliability and maintainability models for mobile underground haulage equipment." CIM Bulletin, Vol. 96, June/July 2003, pp 159-165

12. Kummar, U., Huang, Y., "Reliability Analysis of a mine production System, a case study." Proceedings Annual Reliability and Maintainability Symposium, 1993, pp 167172.

13. Blanchard, B.S., Verma, d., Petersonl, E. 1., Maintainability a Key to Effective Serviceability and Maintenance Management, John Wiley and Sons, 1995.

14. Blischke, W.R., Prabhakar Murthy, D.N., Case Studies in Reliability and Maintenance., John Wiley, USA, 2003. 
15. Vagenas, N., Kazakidis, V., Scoble, M., Espley, S., "Applying a Maintenance Methodology for Excavation Reliability." International Journal of Surface Mining, Reclamation and Environment, 2003, Vol. 17, No. 1, PP. 4-19.

\section{BIOGRAPHY}

Javad Barabady

Division of Operation and Maintenance
Department of Civil and Environment Engineering Luleå University of Technology, SE-971 87 Luleå, Sweden

E-mail: Javad.Barabady@1tu.se

Javad Barabady is a Ph.D. student at Division of Operation and Maintenance Engineering; Luleå University of Technology and his research topic is reliability analysis of mining system. He also received his M.Sc. degree in 1998 in the filed of mining engineering from Tehran University 